\section{International Scientific Journal Theoretical \& Applied Science}

p-ISSN: 2308-4944 (print) e-ISSN: 2409-0085 (online)

Year: $2018 \quad$ Issue: $03 \quad$ Volume: 59

Published: $30.03 .2018 \quad$ http://T-Science.org
Elnura Bunyat Mamedova

Doctor of Philosophy in Economics, Head of the Department of «Finance and Banking», Azerbaijan University of Cooperation Baku, Azerbaijan Republic

SECTION 31. Economic research, finance, innovation, risk management.

\title{
ACTUAL PROBLEMS OF FORMING AND PROVIDING THE RATIONALITY OF INVESTMENT CLIMATE IN THE AGRICULTURE SPHERE OF AZERBAIJAN
}

\begin{abstract}
The actual problems and questions on formation and maintenance of rationality of an investment climate in agrarian sphere of Azerbaijan are considered in the article. The formation of the legislative base for ensuring the protection of foreign investments and the organization of investment activity in Azerbaijan is analyzed.State approaches and mechanisms for regulating investment activities, ensuring investment attractiveness of the agricultural sector, mechanisms for assisting entrepreneurs in attracting investments, and other issues related to investment activity are considered.The necessity of improving existing mechanisms for attracting foreign investments into the country's agrarian sphere is substantiated.A number of specific issues on the organization and development of regional mechanisms for enhancing the investment activities of agrarian entities in the regions of the country are considered.A number of recommendations and suggestions to intensify investment attraction in the country's agrarian sector within the framework of strategic road maps in the near and long termare summarized and made.

Key words: agrarian sector, the agrarian sector of Azerbaijan, the attractiveness of the investment climate of the agrarian sector, the rationality of the investment climate of the agrarian sector of Azerbaijan, the current problems of ensuring the investment attractiveness of the agricultural sector

Language: Russian

Citation: Mamedova EB (2018) ACTUAL PROBLEMS OF FORMING AND PROVIDING THE RATIONALITY OF INVESTMENT CLIMATE IN THE AGRICULTURE SPHERE OF AZERBAIJAN. ISJ Theoretical \& Applied Science, 03 (59): 307-312.

Soi: http://s-o-i.org/1.1/TAS-03-59-51 Doi: crossef https://dx.doi.org/10.15863/TAS.2018.03.59.51
\end{abstract}

\section{АКТУАЛЬНЫЕ ПРОБЛЕМЫ ФОРМИРОВАНИЯ И ОБЕСПЕЧЕНИЯ РАЦИОНАЛЬНОСТИ ИНВЕСТИЦИОННОГО КЛИМАТА В АГРАРНОЙ СФЕРЕ АЗЕРБАЙДЖАНА}

Аннотация: В статье рассмотрены актуальные проблемы и вопросы по формированию и обеспечению рациональности инвестиционного климата в аграрной сфере Азербайджана. Анализировано формирование законодательной базы обеспечения защчиты иностранных инвестиций и организации инвестиционной деятельности в Азербайджане. Рассмотрены государственные подходы и механизмы регулирования инвестиционной деятельности, обеспечение инвестиционной привлекательности аграрного сектора, механизмы помощи предпринимателям по привлечению инвестиций и прочие другие вопросы, связанные с инвестиционной активностью. Обоснована необходимость совершенствования существуюших механизмов по привлечению иностранных инвестиций в аграрную сферу страны. Рассмотрен ряд конкретных вопросов по организации и развитию региональных механизмов для активизации инвестиционной деятельности аграрных субъектов в регионах страны. Обобщен ряд рекомендаций и даны предложения по интенсификаџии привлечения инвестиций в аграрный сектор страны в рамках стратегических дорожных карт в ближайшей и долгосрочной перспективе.

Ключевые слова: аграрный сектор, аграрная сфера Азербайджана, привлекательность инвестициионого климата аграрного сектора, рациональность инвестиционного климата аграрной сферы Азербайджана, актуальные проблемы обеспечения инвестиционной привлекательности аграрного сектора 


\section{Introduction}

В условиях роста глобальных экономических влияний и трансформации основных конструкций мирохозяйственной системы обуславливаются новые подходы и механизмы по обеспечению эффективности национальной экономики, ее устойчивости и прочности. Более того, финансовые лихорадки и кризис, экономические трудности и проблемы последних лет в мире поставили перед правительствами стран новые актуальные проблемы - по совершенствованию основных механизмов финансовых и экономических основ экономики страны, повышению инвестиционной активности и обеспечению привлекательности инвестиционного климата в стране, в том числе активизации привлечения прямых иностранных инвестиций.

\section{Materials and Methods}

Азербайджан, после восстановления своего суверенитета, с распадом бывшего СССР, получил тяжелые последствия по структуре экономики, особенно в аграрной сфере. Аграрная сфера страны надолго была лишена возможности модернизации и обновления современного оборудования, не имела самостоятельные финансовые и инвестиционные механизмы и не имела прав самой привлекать иностранные инвестиции. Однако в начале 90-х годов XX века в корне все изменилось и Азербайджан, в качестве независимого государства проводил огромную работу по организации и развитию самостоятельных государственных атрибутов, в том числе в сфере инвестиционной деятельности и развития аграрной сферы с совершенствованием ее финансовых и инвестиционных механизмов. Так, сразу после восстановления независимости, одним из первых законов в стране был Закон Азербайджанской Республики «О защите иностранных инвестиций», который был принят 15 января 1992 года, спустя несколько лет, 13 января 1995 года, был разработан и принят другой закон - Закон Азербайджанской Республики «Об инвестиционной деятельности», а 22 октября 2010 года был принят Закон Азербайджанской Республики «Об инвестиционных фондах» [1;2;3]. Определены важные и практичные механизмы инвестиционной поддержки предпринимательства и улучшения инвестиционного климата в стране. Так, с Постановлением Кабинета Министров Азербайджанской Республики «Инвестиционная помощь малому предпринимательству» от 16 июня 2001 года были определены и применены основные механизмы организации и обеспечения инвестиционной поддержки субъектов малого предпринимательства [4]. Все эти факторы, также дополнительные меры по развитию предпринимательства и уменьшению вмешательства в их деятельность, остановка массовых проверок субъектов предпринимательства, оказание государственной поддержки по снабжению топливом, минеральными удобрениями и льготными кредитными ресурсами способствовали интенсификации развитию малого и среднего бизнеса в стране и, особенно это почувствовалось в регионах страны. Закон Азербайджанской Республики $\quad$ ॥О предпринимательской деятельности», который был принят 15 декабря 1992 года, способствовал активному переходу от административно-централизованной командноуправленческой системы хозяйства к принципам рыночных отношений и углубления рыночного хозяйства в стране [5].

Как известно, аграрная сфера в Азербайджане считается стратегическим сектором экономики страны, так как от ее стабильной деятельности, устойчивости и конкурентоспособности зависит обеспечение продовольственной безопасности населения, минимизации зависимости продовольственного обеспечения от импорта и, в целом укрепление экономической безопасности страны в условиях расширения глобальных угроз и влияний. 16 апреля 2014 года был издан Указ Президента Азербайджанской Республики «О мероприятиях ускорения институциональной реформы и совершенствования управления в аграрной сфере», где были определены важные направления институциональной реформы и модернизации государственных механизмов в данной сфере [6]. Начались масштабные работы по углублению институциональной реформы в аграрной сфере, создан ряд государственных структур, корпораций и организаций по обеспечению интенсификации развития аграрного сектора, повышению активности аграрных субъектов по наращиванию, сбору и экспорта широкого ассортимента сельскохозяйственной и аграрной продукции, стимулировалось развитие ряда перспективных отраслей растениеводства, таких как хлопководство, чаеводство, табаководство, расширилась деятельность в сфере шелководства, серьезно повысился объем экспорта ряда продукций - помидора, фундука, других фруктов и овощей. Все эти факторы свидетельствуют о серьезном потенциале аграрной сферы страны и eе инвестиционной привлекательности. Более того, 14 июня 2016 года был принят Закон Азербайджанской Республики «О кооперации сельского хозяйства», который дал возможность расширению финансово-инвестиционной деятельности в сельскохозяйственном и аграрном секторе [7]. 
Однако, несмотря на то, что государство принимает последовательные меры и старается выполнять крупномасштабные задачи по модернизации и развитию аграрной сферы, к большому сожалению пока не удалось обеспечить ее инвестиционную привлекательность и в целом рациональность инвестиционного климата. Государство само активно помогает аграрному сектору, даже обеспечивает сельскохозяйственной техникой через свои организованные структуры. Ранее также мы говорили, что субъектам аграрной сферы представляются льготные сельскохозяйственные удобрения, кредиты, однако иностранные инвестиции, да и прямые внутренние инвестиции в аграрную сферу имеют низкой активности. В аграрной сфере идет интенсификация производственно-агарных отношений, создаются немалые субъекты в качестве фермерских хозяйств и сельскохозяйственных предприятий, которые занимаются производством продовольственных и пищевых продукций, постоянно нуждаются в высоких технологиях, новых оборудованиях и для этого требуется инвестиционные ресурсы. Bсе эти проблемы отражены в стратегических документах страны и государственных программах. Так, в рамках реализации государственной программы социальноэкономического развития регионов Азербайджанской Республики на 2014-2018 годы, предусмотрены разработка и реализация комплексных мероприятий и механизмов по развитию инвестиционной деятельности в аграрной сфере и тем самым обеспечить рациональность инвестиционного климата в нем [8]. Кроме того, в «Концепция Развития Азербайджана - 2020: Взгляд в Будущее», утвержденной Указом Президента Азербайджанской Республики от 29 декабря 2012 года также широко освещены актуальные проблемы и приоритетные направления инвестиционной деятельности в ненефтяных секторах экономики страны, в том числе в аграрной сфере [9]. И, наконец, в рамках стратегических дорожных карт, утвержденных Указом Президента Азербайджанской Республики от 6 декабря 2016 года, определены стратегические подходы и цели по развитию аграрной сферы, совершенствованию его основных механизмов, обеспечению инвестиционной привлекательности, развитию механизмов финансирования и страхования [10;11]. Анализ за прошедший период показал, что процессы формирования и обеспечения рациональности инвестиционного климата в аграрной сфере страны набирают обороты, создаются новые крупные фермерские хозяйства и аграрные предприятия. В стране, практически в каждом аграрном районе, намечено создание агропарков и уже в данном направлении идут интенсивные работы. В целом, в 47 районах Азербайджана в ближайшие годы будут созданы современные агропарки, которые сыграют огромную роль по улучшению инвестиционного климата в аграрной сфере страны. По итогам 2017 года, проведен мониторинг инвестиционного рейтинга районов Азербайджана, где была замечена активизация ряда аграрных районов страны по улучшению инвестиционной деятельности и климата, однако в целом, как мы отметили, еще предстоит сделать немало, чтобы смягчить актуальную проблему в данной сфере [12].

Следует подчеркнуть, что актуальные проблемы формирования и обеспечения рациональности инвестиционного климата в аграрной сфере Азербайджана обуславливают повышение эффективности инвестиционной деятельности государства, существенное обновление и разработку новых механизмов активизации инвестиционной деятельности в аграрной сфере, диверсификации основных источников финансов развития аграрной сферы. Исследователи И.Алыев, Ш.Мамедова, В.М.Сулейманов, Т.Т.Абдулгасанов изучили актуальные проблемы в данных направлениях [13;14;15]. Можно отметить, что образовалось твердое мнение о неадекватности существующих финансовых и инвестиционных механизмов аграрной сфере в нынешних условиях, где отсутствуют более продуктивные и рациональные механизмы по улучшению инвестиционного климата в аграрной сфере страны. На наш взгляд, авторы в данных подходах совершенно правы, так как инвестиционная активность в аграрной сфере невелика и не представляет собой серьезные намерения, проекты, механизмы в данном направлении. Кроме того, иностранные инвестора не спешат вкладывать серьезные инвестиционные и финансовые ресурсы в аграрную сферу Азербайджана. Ряд исследователей отмечают, что данная проблема характерна для всех аграрных субъектов постсоветских республик, где риск вклада иностранных инвестиций остается высоким, так как существующие механизмы по организации и привлечению иностранных инвестиций не обеспечены полной прозрачностью и в этих странах аграрный сектор находится под влиянием монопольных структур и холдингов. То есть, пока не обеспечена полноценная здоровая конкурентная среда и привлекательный инвестиционный климат в агарной сфере. Исследователь С.А.Антипин, Н.П.Ильин, Н.А.Шабунин и Ф.М-Г.Топсахалова в числе актуальных проблем формирования и обеспечения рациональности инвестиционного климата в аграрной сфере выделяют такие 


\begin{tabular}{|c|c|c|c|c|c|c|}
\hline Impact Factor: & $\begin{array}{l}\text { ISRA (India) } \\
\text { ISI (Dubai, UAE } \\
\text { GIF (Australia) } \\
\text { JIF }\end{array}$ & $\begin{array}{r}=1.344 \\
=0.829 \\
=0.564 \\
=1.500\end{array}$ & $\begin{array}{l}\text { SIS (USA) } \\
\text { PИНЦ (Russia) } \\
\text { ESJI (KZ) } \\
\text { SJIF (Morocco) }\end{array}$ & $\begin{array}{l}=0.912 \\
=0.207 \\
=4.102 \\
=2.031\end{array}$ & $\begin{array}{l}\text { ICV (Poland) } \\
\text { PIF (India) } \\
\text { IBI (India) }\end{array}$ & $\begin{array}{l}=6.630 \\
=1.940 \\
=4.260\end{array}$ \\
\hline
\end{tabular}

пробелы, как неадекватность организационноэкономических механизмов, неадекватность стратегического управления в аграрной сфере, неэффективность

механизмов привлеченииинвестиций в развитие агропромышленного комплекса и необходимость совершенствования основных критерий оценки инвестиционной привлекательности аграрного сектора $[16 ; 17 ; 18 ; 19]$. Однако на наш взгляд, аграрная сфера Азербайджана отличается специфической чертой, так как в Азербайджане имеются все виды природных ресурсов и условий для интенсивного и продуктивного развития сельского хозяйства и создания мощного потенциала для перерабатывающих предприятий агропромышленного сектора, то есть имеются достаточные ресурсы для повышения инвестиционной привлекательности данной сферы. Профессора А.Х.Нуриев, С.В.Салахов, Б.Х.Аташов и И.Х.Ибрагимов отметили инвестиционный потенциал и возможность форсирования инвестиционной деятельности, развития финансовых механизмов в аграрном секторе страны [20;21;22;23]. Но как мы отметили, пока инвестиционная активность оценивается ниже своих возможностей. Считаем, что необходимо существенно усилить роль по формированию и обеспечению рациональности инвестиционного климата в аграрную сферу крупных банков Азербайджана.

На Рис. 1 дан объем кредитных портфелей наиболее крупных банков Азербайджана на начало 2017 года.

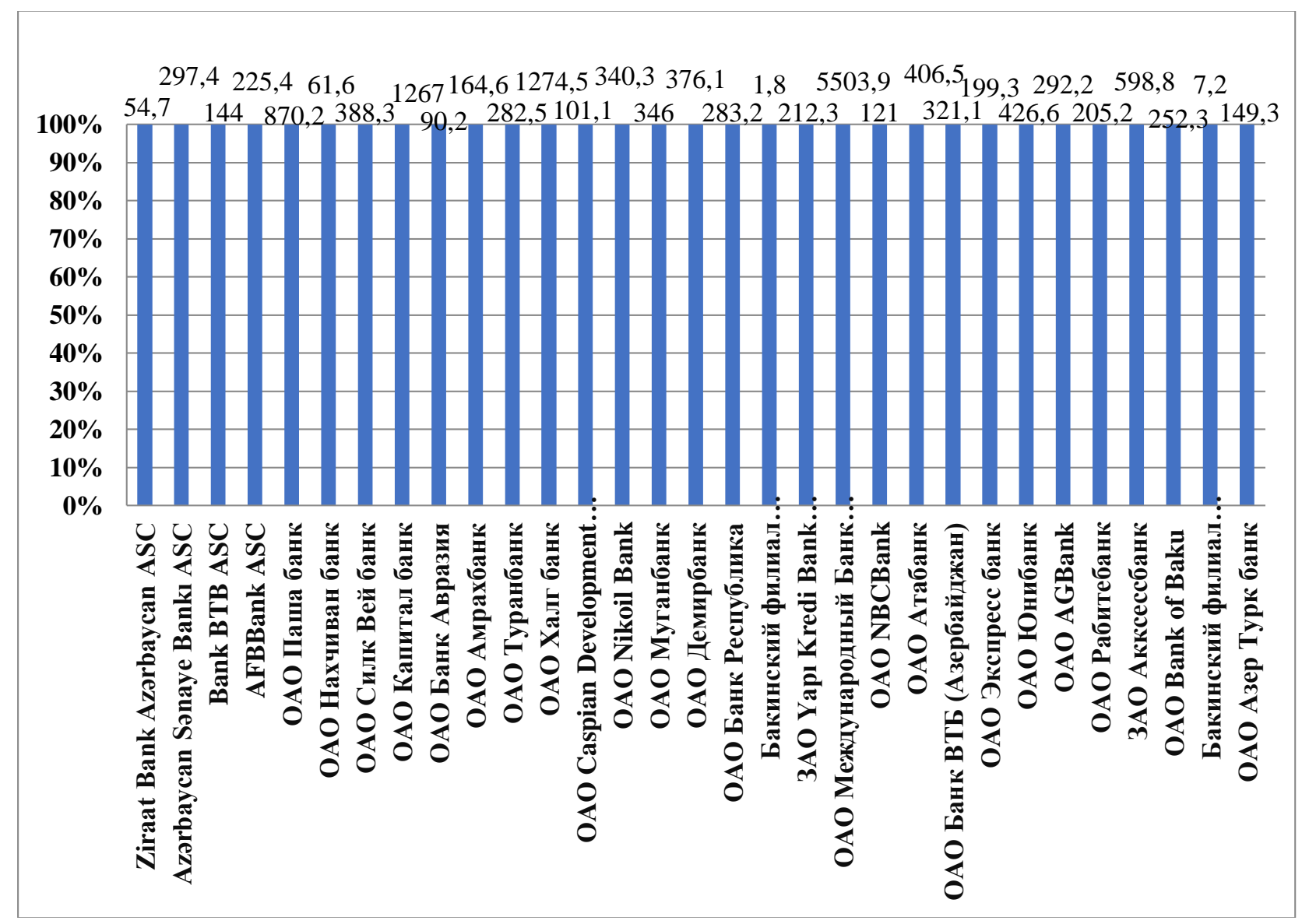

Рис.1. Объем кредитных портфелей наиболее крупных банков Азербайджана на начало 2017 года, млн. манат (подготовлено автором по материалам Азербайджанских Банковских Ассоциаций).

А на Рис. 2 отражены объем кредитных вложений экономики со стороны коммерческих банков Азербайджана. 


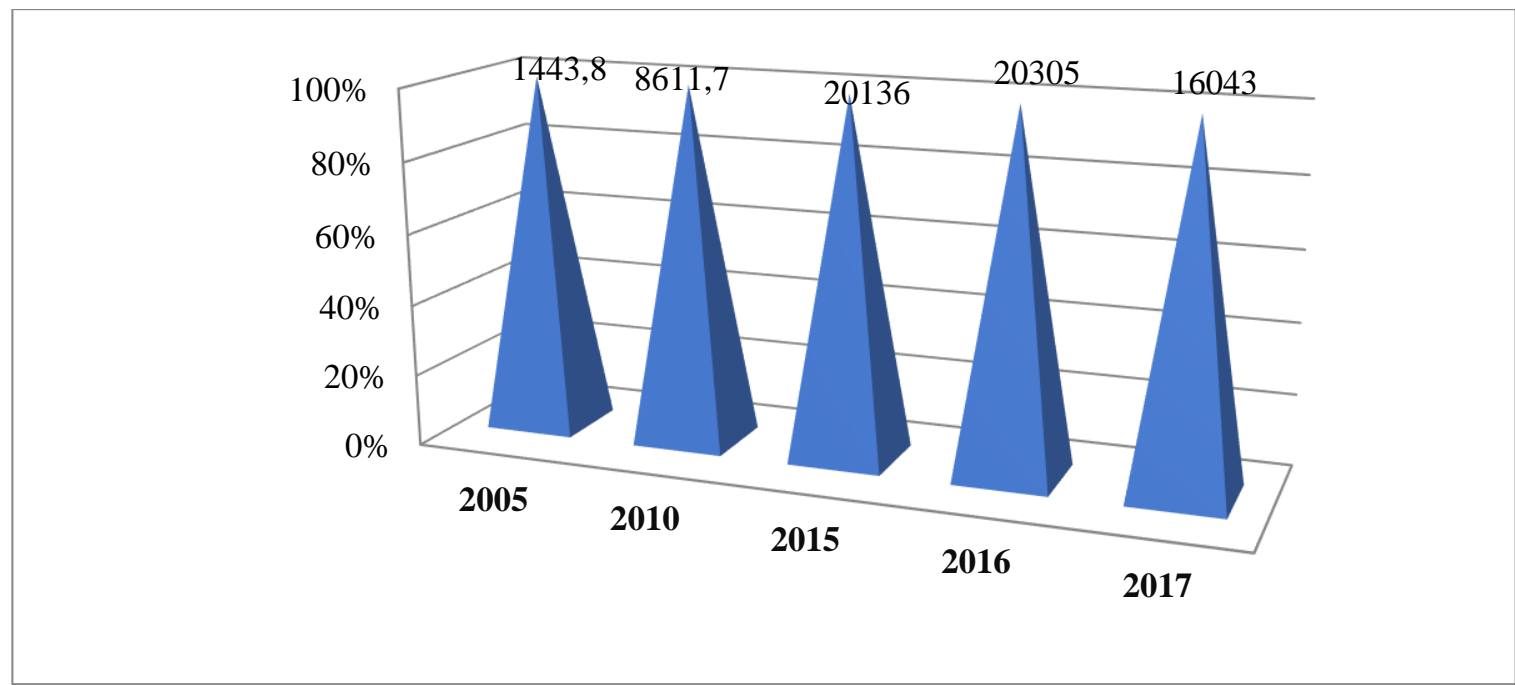

Рис. 2. Объем кредитных вложений экономики страны со стороны коммерческих банков Азербайджана, млн. манат (подготовлено автором по материалам Азербайджанских Банковских Ассоциаций http://www.aba.az).

Как видно, из Рис. 2, объем кредитных вложений в экономику страны со стороны коммерческих банков в 2017 году уменьшился по сравнению с 2016 годом, который требует новые механизмы и серьезные меры, адекватные нынешним критериям развития экономики страны.

\section{Conclusion}

Отметим, что аграрная сфера Азербайджана характеризуется мощным потенциалом по созданию добавочной стоимости и повышения экспортного потенциала страны. Исследователи В.А.Гасымлы, Р.З.Гусейн, Т.И.Керимова, М.Гюльалиев и Р.Алиев отмечают важность комплексного и системного решения существенных проблем формирования и обеспечения рациональности инвестиционного климата в аграрной сфере $[24 ; 25 ; 26 ; 27 ; 28]$. Мы считаем, что нуждаются в серьезной необходимости совершенствование существующих подходов и механизмов инвестиционной деятельности в аграрной сфере и проводимые работы с иностранными инвесторами. Необходимо активно воспользоваться более прогрессивными методами объективной оценки инвестиционной привлекательности, с учетом рентабельности инвестиций и метода срока окупаемости. Целесообразно более активное привлечение инвестиционной деятельности коммерческих банков, инвестиционных фондов и крупных инвестиционных организаций мира, которые специализируются на деятельности аграрного сектора. Нуждается в активизации инвестиционно-инновационная деятельность в аграрной сфере, в повышении эффективности региональных инвестиционных фондов и организаций, финансово-кредитных учреждений, страховые компаний и в целом обеспечить максимальную привлекательность инвестиций в аграрной сфере Азербайджана в ближайшей перспективе.

\section{References:}

1. (1992) Zakon Azerbaydzhanskoy Respubliki «O zashchite inostrannykh investitsiy».g. Baku, 15 yanvarya 1992 goda, № 57.

2. (1995) Zakon Azerbaydzhanskoy Respubliki «Ob investitsionnoy deyatel'nosti» ot 13 yanvarya 1995 goda, №952.
3. (2010) Zakon Azerbaydzhanskoy Respubliki «Ob investitsionnykh fondakh». Baku, 22 oktyabrya 2010 goda №1101-IIIQ.

4. (2001) Postanovleniye Kabineta Ministrov Azerbaydzhanskoy Respubliki «Investitsionnaya pomoshch' malomu 


\begin{tabular}{|c|c|c|c|c|c|c|}
\hline Impact Factor: & $\begin{array}{l}\text { ISRA (India) } \\
\text { ISI (Dubai, UAE } \\
\text { GIF (Australia) } \\
\text { JIF }\end{array}$ & $\begin{array}{l}=1.344 \\
=0.829 \\
=0.564 \\
=1.500\end{array}$ & $\begin{array}{l}\text { SIS (USA) } \\
\text { PИНЦ (Russia) } \\
\text { ESJI (KZ) } \\
\text { SJIF (Morocco) }\end{array}$ & $\begin{array}{l}=0.912 \\
=\mathbf{0 . 2 0 7} \\
=\mathbf{4 . 1 0 2} \\
=\mathbf{2 . 0 3 1}\end{array}$ & $\begin{array}{l}\text { ICV (Poland) } \\
\text { PIF (India) } \\
\text { IBI (India) }\end{array}$ & $\begin{array}{l}=6.630 \\
=1.940 \\
=4.260\end{array}$ \\
\hline
\end{tabular}

predprinimatel'stvu». Baku, 16 iyunya 2001, №101.

5. (1992) Zakon Azerbaydzhanskoy Respubliki «O predprinimatel'skoy deyatel'nosti». Baku, 15 dekabrya 1992 god, №405.

6. (2014) Ukaz Prezidenta Azerbaydzhanskoy Respubliki «O meropriyatiyakh uskoreniya institutsional'noy reformy i sovershenstvovaniya upravleniya $\mathrm{v}$ agrarnoy sfere». Baku, 16 aprelya 2014 god, № 152 .

7. (2016) Zakon Azerbaydzhanskoy Respubliki «O kooperatsii sel'skogo khozyaystva». Baku, 14 iyunya 2016 god.

8. (2018) Gosudarstvennaya programma sotsial'no-ekonomicheskogo razvitiya regionov Azerbaydzhanskoy Respubliki v 2014-2018 godakh.

9. (2012) Kontseptsiya Razvitiya Azerbaydzhana - 2020: Vzglyad v Budushcheye. Utverzhdeno Ukazam Prezidenta Azerbaydzhanskoy Respubliki ot 29 dekabrya 2012 goda. Baku, 2012.- 39 p.

10. (2016) Strategicheskiye dorozhnyye karty po natsional'noy ekonomike i osnovnym sektorom ekonomiki. Ukaz Prezidenta Azerbaydzhanskoy Respubliki. Baku, 6 dekabrya 2016 goda.

11. (2016) Strategicheskiye dorozhnyye karty opo proizvodstvu i pererabotke produktsii sel'skogo khozyaystva v Azerbaydzhanskoy Respublike. Utverzhdeno Ukazom Prezidenta Azerbaydzhanskoy Respubliki ot 6 dekabrya 2016 goda. $-177 \mathrm{p}$.

12. (2017) Investitsionnyy reyting rayonov. Tsentr Analiza Ekonomicheskikh Reform i Kommunikatsii. Baku, 19 aprelya 2017 god- 8 p. Available: http://ecoreform.az (Accessed: 10.03.2018).

13. Alyyev I., Mamedova SH. (2007) Osnovnyye istochniki finansov razvitiya agrarnoy sfery. Baku, «Nauka», 2007.

14. Suleymanov V.M. (2009) Voprosy povysheniya effektivnosti investitsionnoy deyatel'nosti gosudarstva. Avtoreferat diss. kand. ekon. nauk. Baku, 2009.-26 p.

15. Abdulgasanov T.T. (2014) Investitsionnyy klimat Azerbaydzhanskoy Respubliki, kak klyuchevoy faktor razvitiya sel'skogo khozyaystva // Zhurnal Ekonomika APK, №12, 2014.-p. 97-102.

16. Antipin S.A. (2006) Formirovaniye sistemy organizatsionno-ekonomicheskikh otnosheniy $\mathrm{v}$ agrarnoy sfere. Diss. d-ra ekon. nauk. SanktPeterburg, 2006.-279 p.

17. Il'in N.P. (2007) Paradigma strategicheskogo upravleniya $\mathrm{v}$ agrarnom sektore ekonomiki $\mathrm{v}$ usloviyakh reformirovaniya: teoriya, metodologiya, praktika. Diss. d-ra ekon. nauk. Sankt-Peterburg, 2007.-324 p.

18. Shabunin N.A. (2011) Privlecheniye investitsiy $\mathrm{v}$ razvitiye agropromyshlennogo kompleksa Rossii. Diss. kand. ekon. nauk. Moskva, 2011.

19. Topsakhalova F.M-G. (2006) Teoreticheskiye i metodologicheskiye osnovy otsenki investitsionnoy privlekatel'nosti agrarnogo sektora. Diss. d-ra ekon. nauk. Stavropol', 2006.-419 p.

20. Nuriyev A.KH. (2007) Osnovy regional'nogo upravleniya. Akademiya Gosudarstvennogo Upravleniya pri Prezidente Azerbaydzhanskoy Respubliki, Baku: Nauka, 2007.- 428 p.

21. Salakhov S.V. (2004) Problemy gosudarstvennogo regulirovaniya agrarnogo sektora. Baku, 2004.-504 p.

22. Atashov V.KH. (2017) Problemy struktury i effektivnosti v agrarnoy sfere: teoriya i praktika (monografiya). Baku:kooperatsiya, 2017.- 535 p.

23. Ibragimov I.KH. (2016) Ekonomika agrarnoy sfery. Monografiya, Baku, 2016.-655 p

24. Gasymly V.A. (2017) Ekonomicheskiye problemy modernizatsii agrarnoy sfery. Avtoreferat diss. d-ra ekon. nauk. Baku, 2017.$51 \mathrm{p}$.

25. Gasymov V.A. (2009) Rol' gosudarstvennogo regulirovaniya investitsionnoy deyatel'nosti $\mathrm{V}$ agrarnom sektore Azerbaydzhana // Mezhdunarodnyy tekhniko-ekonomicheskiy zhurnal, Izdatel'stvo: Uchebno-metodicheskiy tsentr «Triada» (Moskva), №1, 2009.-p.- 1619.

26. Kerimova T.I. (2008) Investitsionnyy potentsial ekonomiki: mekhanizmy formirovaniya $i$ ispol'zovaniya. Baku, 2008.- 225 p.

27. Guseyn R.Z. (2017) Problemy povysheniya konkurentosposobnosti produktsii rasteniyevodstva V Azerbaydzhankoy Respublike. Avtoreferat diss. d-ra ekon. nauk. Baku, 2017.-56 p.

28. Gyul'aliyev M., Aliyev R. (2015) Dinamika i otraslevaya struktura inostrannykh investitsiy, napravlennykh v ekonomiku Azerbaydzhana // Ekonomicheskiy Vestnik Donbassa, №3 (41), 2015.-p. 67-74. 